\title{
Screening Colonoscopies by Primary Care Physicians: A Meta-Analysis
}

\author{
Thad Wilkins, $M D^{1}$ \\ Bruce LeClair, MD, MPH \\ Mark Smolkin, MS ${ }^{2}$ \\ Katby Davies, MLS $S^{3}$ \\ Andria Thomas, $P b D^{1}$ \\ Marcia L. Taylor, MD, MSCR ${ }^{4}$ \\ Scott Strayer, MD, MPH \\ 'Department of Family Medicine, Medical \\ College of Georgia, Augusta, Georgia \\ ${ }^{2}$ Department of Public Health Sciences, \\ University of Virginia Health System, \\ Charlottesville, Virginia \\ ${ }^{3}$ Department of Education and Informa- \\ tion Services, Medical College of Georgia, \\ Augusta, Georgia \\ ${ }^{4}$ Lexington Medical Center, Lexington, \\ South Carolina \\ ${ }^{5}$ Department of Family Medicine, Univer- \\ sity of Virginia Health System, Charlottes- \\ ville, Virginia \\ Th \\ MORE ONLINE \\ www.annfammed.org
}

Conflicts of interest: The authors declare no potential, perceived, or real conflict of interest.

\section{CORRESPONDING AUTHOR}

Thad Wilkins, MD

Medical College of Georgia, HB-4031

Augusta, GA 30912

twilkins@mcg.edu

\begin{abstract}
PURPOSE There is currently too few endoscopists to enact a national colorectal cancer screening program with colonoscopy. Primary care physicians could play an important role in filling this shortage by offering screening colonoscopy in their practice. The purpose of this study was to examine the safety and effectiveness of colonoscopies performed by primary care physicians.
\end{abstract}

METHODS We identified relevant articles through searches of MEDLINE and EMBASE bibliographic databases to December 2007 and through manual searches of bibliographies of each citation. We found 590 articles, 12 of which met inclusion criteria. Two authors independently abstracted data on study and patient characteristics. Descriptive statistics were performed. For each outcome measure, a random effects model was used to determine estimated means and confidence intervals.

RESULTS We analyzed 12 studies of colonoscopies performed by primary care physicians, which included 18,292 patients (mean age 59 years, 50.5\% women). The mean estimated adenoma and adenocarcinoma detection rates were $28.9 \%$ (95\% confidence interval [Cl], 20.4\%-39.3\%) and 1.7\% (95\% Cl, 0.9\%-3.0\%), respectively. The mean estimated reach-the-cecum rate was $89.2 \%(95 \% \mathrm{Cl}$, $80.1 \%-94.4 \%)$. The major complication rate was $0.04 \%$ ( $95 \% \mathrm{Cl}, 0.01 \%-0.07 \%)$; no deaths were reported.

CONCLUSIONS Colonoscopies performed by primary care physicians have quality, safety, and efficacy indicators that are comparable to those recommended by the American Society of Gastrointestinal Endoscopy, the American College of Gastroenterology, and the Society of American Gastrointestinal Endoscopic Surgeons. Based on these results, colonoscopy screening by primary care physicians appears to be safe and effective.

Ann Fam Med 2009;7:56-62. DOI: 10.1370/afm.939.

\section{INTRODUCTION}

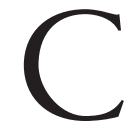

olorectal cancer ${ }^{1-4}$ is the third most common cancer and second leading cause of cancer mortality in the United States. ${ }^{5}$ Guide-

lines recommend colonoscopy as a suitable screening method, ${ }^{1,4,6,7}$ and evidence is increasing that colonoscopy may be the most cost-effective approach. ${ }^{3,8-14}$ As a result, the demand for screening colonoscopy is rapidly growing. The resources needed to screen every eligible person using colonoscopy do not currently exist in the US medical system, however, ${ }_{1}^{15}$ and fewer than one-third of those who are eligible for colonoscopy are screened. ${ }^{3,16}$

There has been a recent call for monitoring quality indicators in endoscopy to support continuous quality improvement among endoscopists. Proposed measures for quality include reach-the-cecum rates, adenoma detection rates, advanced adenoma detection rates, and withdrawal times. ${ }^{14,17,18}$ In the United States, a comprehensive task force of the American Society of Gastrointestinal Endoscopists and the American College of Gastroenterology has recommended acceptable standards for these qual- 
ity measures based on a comprehensive review of the literature. ${ }^{19}$ In the United Kingdom, the Joint Advisory Group on GI Endoscopy (JAG) established standards for colonoscopies regardless of specialty. These standards state that a colonoscopist perform at least 150 colonoscopies during training, perform 150 colonoscopies annually, and have a reach-the-cecum rate of at least $90 \% .^{20}$

No systematic data are available that document the safety and efficacy of primary care physicians in performing screening colonoscopies. The purpose of this study was to perform a systematic review and metaanalysis of studies that evaluated the quality and safety of screening colonoscopies performed by primary care physicians.

\section{METHODS}

\section{Data Sources and Searches}

A literature search was conducted in MEDLINE from 1966 to December 2007 and EMBASE from 1974 to December 2007 to retrieve all articles addressing colonoscopy performed by primary care physicians. To ensure complete retrieval of information, the search topics were expanded to include the practice of primary care physicians, family physicians, internists, and colorectal cancer. The primary care concept would thus include all clinical care settings, such as private practice, hospital, and rural physicians. MeSH terms and the search strategy are listed in the Supplemental Appendix,

available online at http://www.annfammed.org/cgi/ content/full/7/1/56/DC1. Reference lists of included studies were systematically reviewed for additional studies. In addition, researchers and experts belonging to a listserv of primary care endoscopists were asked to provide lists of relevant studies and unpublished studies.

\section{Study Selection}

A study was included in the meta-analysis if it reported on colonoscopies performed by primary care physicians, defined as family physicians, internists, obstetricians and gynecologists, and general practitioners. The studies included retrospective cohort studies as well as 1 case-control study. Studies were excluded if they were nonclinical or did not provide outcome data on the colonoscopies or if the colonoscopies were not performed by primary care physicians. All potentially eligible trial reports were read by 2 authors of this study (T.W., B.L.), and disagreements concerning eligibility were resolved by discussion.

\section{Data Extraction and Quality Assessment}

Two of the authors (T.W., B.L.) independently reviewed each study and extracted the study and patient characteristics. These characteristics included patient demographics, adenoma and adenocarcinoma detection rates, reach-the-cecum rates, use of sedation, training of endoscopists, and major complications, including death, perforation, and bleeding.

\section{Data Synthesis and Analysis}

Although many studies in our series involved more than 1 colonoscopist, most did not report outcomes by the individual colonoscopist ${ }_{i}$ instead, they reported only aggregate outcomes. Initial examination for the presence of heterogeneity in reach-the-cecum rate across studies was performed using the $\chi^{2}$ test of association. For each of 4 binomially distributed outcomes (reach-the-cecum rates for both sedated and unsedated patients, adenoma detection rates, and adenocarcinoma detection rates), we fit logistic regression models using the GLIMMIX procedure in SAS 9.1 (SAS Institute, Cary, North Carolina). Each model included an intercept and study factor, with the study factor (representing each of the 12 included studies) treated as a random effect. This random effects modeling enabled assessment of the between-study variability for each outcome and accounted for differences in the number of procedures per study to obtain an overall estimate for each outcome measure. Predicted values obtained from each model were transformed using this procedure to provide both overall and study-specific estimated success rates and 95\% confidence intervals (CIs).

Quality scores, such as Jadad score, have been used in the meta-analysis of randomized clinical control trials. ${ }^{21}$ No quality score has been developed for the use of nonrandomized studies, however, and the use of quality scores in meta-analysis of observational studies is controversial and may lack proven validity. ${ }^{22}$ Accordingly, no quality scores were computed for the individual studies. We did, however, adhere to the guidelines for reporting meta-analysis of observational studies in epidemiology (MOOSE guidelines). ${ }^{23}$

\section{RESULTS}

Our search found 590 potentially eligible trials. We subsequently excluded 578 trials for the following reasons: 140 were for colorectal cancer screening in general; 121 were not specific to colonoscopy; and the remaining 317 studies met other criteria for exclusion, such as resident education in colonoscopy, patient compliance with screening recommendations, and the capacity to perform colonoscopy. Figure 1 displays the search results and study flow diagram. The analysis therefore included 12 trials. There were 11 retrospective cohort studies and 1 case-control study. Table 1 summarizes the study characteristics. No randomized trials, systematic reviews, or meta-analysis were identified. 
Table 2 summarizes the results of the analysis. These 12 studies included a pooled sample size of 18,292 patients. The mean age was 59 years, and $50.5 \%$ were women. Using the random effects models, the estimated mean adenoma detection rate was

Figure 1. Search results and study flow diagram.

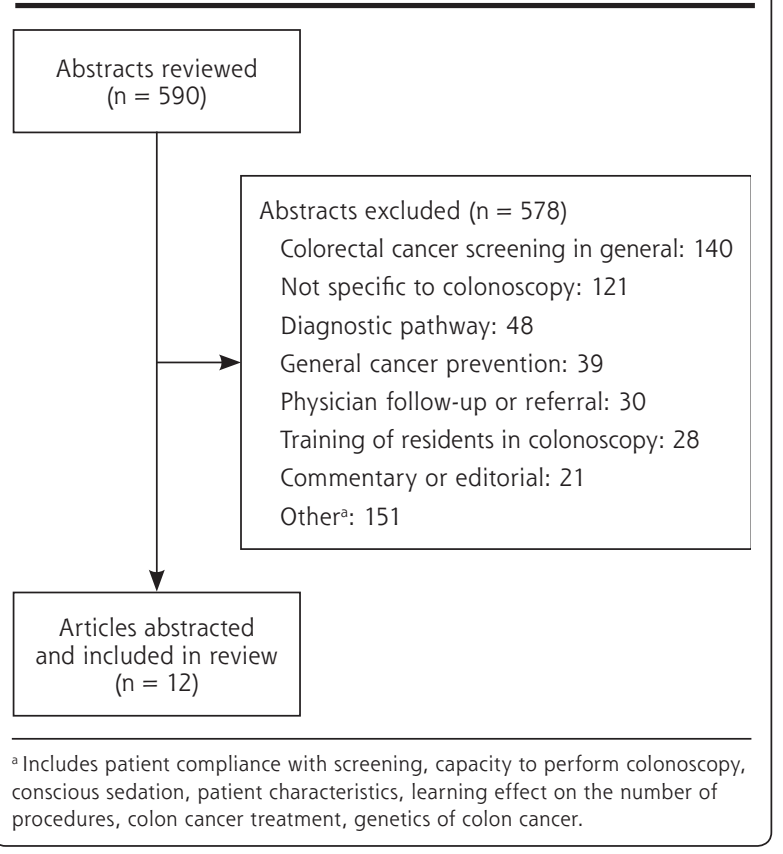

$28.9 \%(95 \% \mathrm{CI}, 20.4 \%-39.3 \%)$ and the estimated mean adenocarcinoma rate was $1.7 \%$ (95\% CI, $0.9 \%$ $3.0 \%)$. The estimated mean reach-the-cecum rate was $89.2 \%$ (95\% CI, 80.1\%-94.4\%). A $\chi^{2}$ test of association found that reach-the-cecum rates varied significantly between the studies $(P<.001)$. Figures 2 and 3 display the forest plots of adenoma detection rates and reachthe-cecum rates. No deaths were reported in any of the studies. There were 4 patients with bleeding complications and 3 patients with colonic perforations, resulting in a major complication rate of $0.04 \%(95 \%$ CI, 0.01\%-0.07\%).

Funnel plots (Supplemental Figures 1-3, available online at http://www.annfammed.org/cgi/content/ full/7/1/56/DC1) were generated for adenoma and adenocarcinoma detection rates and reach-thececum rates. There was a mostly symmetric distribution in the funnel plots for adenoma detection rates and reach-the-cecum rates, indicating an absence of publication bias. That the funnel plot for adenocarcinoma detection rates is less symmetric may indicate the presence of publication bias for this outcome.

\section{DISCUSSION}

It has been suggested that $90 \%$ or more of all colonoscopies should reach-the-cecum and that it should increase to $95 \%$ or higher when the indication is for

Table 1. Summary of Studies

\begin{tabular}{|c|c|c|c|c|c|c|}
\hline Study, Year & $\begin{array}{l}\text { No. of } \\
\text { Colonoscopies }\end{array}$ & $\begin{array}{l}\text { No. of } \\
\text { Colonoscopists }\end{array}$ & $\begin{array}{l}\text { Average Age, } \\
\text { y (Range) }\end{array}$ & $\%$ Female & Setting & $\begin{array}{l}\text { Study } \\
\text { Design }\end{array}$ \\
\hline Godreau, $^{24} 1992$ & 157 & 1 & $\begin{array}{l}58 \text { (range not } \\
\text { reported) }\end{array}$ & 57.1 & US family practice & Cohort \\
\hline Rodney et al, ${ }^{25} 1993$ & 293 & 1 & $\begin{array}{l}67 \text { (range not } \\
\text { reported) }\end{array}$ & 60.6 & US family practice & Cohort \\
\hline Hopper et al, ${ }^{26} 1996$ & 1,048 & 1 & $57(14-91)$ & 41.3 & US family practice & Cohort \\
\hline Harper et al, ${ }^{27} 1997$ & 309 & 2 & Not reported & Not reported & US family practice & Case-control \\
\hline $\begin{array}{l}\text { Pierzchajio et al, }{ }^{28} \\
\quad 1997\end{array}$ & 751 & 1 & $\begin{array}{l}53.8 \text { (range } \\
\text { not reported) }\end{array}$ & 62.5 & US family practice & Cohort \\
\hline Carr et al, ${ }^{29} 1998$ & 250 & 1 & $\begin{array}{l}67.4 \text { (range not } \\
\text { reported) }\end{array}$ & 61.6 & US family practice & Cohort \\
\hline Kirby, ${ }^{30} 2004$ & 616 & 1 & $\begin{array}{l}58 \text { (range not } \\
\text { reported) }\end{array}$ & Not reported & $\begin{array}{l}\text { Canadian general } \\
\text { practitioner }\end{array}$ & Cohort \\
\hline $\begin{array}{l}\text { Edwards and } \\
\text { Norris, }{ }^{31} 2004\end{array}$ & 200 & 4 & $62(16-90)$ & 45.5 & US family practice & Cohort \\
\hline $\begin{array}{l}\text { Newman et al, } \\
2005\end{array}$ & 731 & 2 & $62.7(20-92)$ & 51.6 & U.S. family practice & Cohort \\
\hline Strayer, ${ }^{33} 2005^{a}$ & 250 & 4 & $\begin{array}{l}57.1 \text { (range not } \\
\text { reported) }\end{array}$ & 50.4 & US family practice & Cohort \\
\hline $\begin{array}{l}\text { Cotterill et al, } \\
2005\end{array}$ & 324 & 2 & Not reported & Not reported & Canadian family practice & Cohort \\
\hline Lloyd $^{35} 2006^{\mathrm{a}}$ & 13,363 & 53 & Not reported & Not reported & $\begin{array}{l}\text { US multispecialty primary } \\
\text { care endoscopy center }\end{array}$ & Cohort \\
\hline Total & 18,292 & 73 & 59 & 50.5 & & \\
\hline
\end{tabular}


Table 2. Estimated Rates of Colonoscopy Quality Outcomes Using Random Effects Modeling

\begin{tabular}{|c|c|c|c|c|c|}
\hline Study, Year & $\begin{array}{c}\text { Estimated } \\
\text { Adenoma Detection } \\
\text { Rate }(95 \% \mathrm{Cl})\end{array}$ & $\begin{array}{c}\text { Estimated } \\
\text { Adenocarcinoma } \\
\text { Detection Rate } \\
(95 \% \mathrm{Cl})\end{array}$ & $\begin{array}{c}\text { Estimated } \\
\text { Reach-the-Cecum } \\
\text { Rate (All Patients) } \\
(95 \% \mathrm{Cl})\end{array}$ & Perforations $^{a}$ & $\begin{array}{c}\text { Bleeding } \\
\text { Not } \\
\text { Requiring } \\
\text { Transfusion }^{\mathrm{a}}\end{array}$ \\
\hline Godreau, ${ }^{24} 1992$ & 51.7 (44.0- 59.3) & $2.2(0.9-5.7)$ & $83.2(76.6-88.2)$ & 0 & 0 \\
\hline Rodney et al, ${ }^{25} 1993$ & $8.8(6.1-12.5)$ & $2.0(0.9-4.2)$ & $48.7(43.1-54.4)$ & 0 & 0 \\
\hline Hopper et al, ${ }^{26} 1996$ & $43.7(40.7-46.7)$ & Not reported & $74.8(72.1-77.3)$ & 0 & 0 \\
\hline Harper et al27, 1997 & $20.9(16.8-25.8)$ & $3.5(2.0-6.1)$ & $87.1(82.9-90.4)$ & 0 & 0 \\
\hline Pierzchajio et al, ${ }^{28} 1997$ & $24.7(21.7-27.9)$ & $0.6(0.3-1.4)$ & $91.4(89.2-93.2)$ & 0 & 0 \\
\hline Carr et al, ${ }^{29} 1998$ & $33.4(27.9-39.5)$ & $1.9(0.8-4.2)$ & $82.2(77.0-86.4)$ & 0 & 1 \\
\hline Kirby, $^{30} 2004$ & 16.8 (14.0- 19.9) & $2.3(1.4-3.8)$ & $80.1(76.8-83.1)$ & 0 & 0 \\
\hline Edwards and Norris, 2004 & $22.8(17.6-29.0)$ & $2.3(1.0-5.2)$ & $96.1(92.4-98.0)$ & 0 & 0 \\
\hline Newman et al, ${ }^{32} 2005$ & $32.5(29.2-36.0)$ & $0.9(0.5-1.9)$ & 92.7 (90.6- 94.4) & 0 & 1 \\
\hline Strayer, ${ }^{33} 2005^{b}$ & $51.3(45.1-57.3)$ & $0.8(0.3-2.6)$ & $94.6(91.1-96.7)$ & 0 & 0 \\
\hline Cotterill et al, ${ }^{34} 2005$ & $23.9(19.6-28.8)$ & $0.7(0.2-2.2)$ & $94.0(90.9-96.1)$ & 0 & 0 \\
\hline Lloyd, $^{35} 2006^{b}$ & $38.0(37.2-38.8)$ & $5.0(4.6-5.4)$ & $98.4(98.2-98.6)$ & 3 & 2 \\
\hline Total & $28.9(20.4-39.3)$ & $1.7(0.9-3.0)$ & $89.2(80.1-94.4)$ & 3 & 4 \\
\hline \multicolumn{6}{|l|}{$\mathrm{Cl}=$ confidence intervals. } \\
\hline \multicolumn{6}{|c|}{ Note: rates and 95\% Cls calculated using random effect model. } \\
\hline \multicolumn{6}{|c|}{$\begin{array}{l}\text { a Raw data shown. } \\
\text { b Additional information about this study was provided by the author. }\end{array}$} \\
\hline
\end{tabular}

colorectal cancer screening. ${ }^{19,36}$ The reported experience in practice varies. In 1 series of 6 gastroenterology fellows who were in their last 7 months of training and who had already performed a mean of 328 colonoscopies, the reach-the-cecum rate was $86 \%$ (range,

\section{Training of Endoscopists}

Endoscopist completed 86 flexible sigmoidoscopies with biopsy then attended a continuing medical education workshop. He was proctored for 13 colonoscopies

Trained in sigmoidoscopy then began performing colonoscopy after 300 sigmoidoscopies

Completed a didactic course

One endoscopist "trained" by gastroenterologist and general surgeon and other endoscopist "trained" by general surgeon and family physician

Completed 700 flexible sigmoidoscopies then attended a didactic course on colonoscopy. He was precepted for 80 colonoscopies

Attended colonoscopy continuing medical education course then completed 11 proctored colonoscopies with 5 polypectomies. Proctored by a family physician

Completed 30 supervised colonoscopies as part of a general surgery residency training program

Three physicians were trained in family medicine residency programs. One of these physicians proctored the oldest physician until he was proficient in colonoscopy.

Trained in a family medicine residency program. Attended a continuing medical education course. Proctored by a gastroenterologist

All physicians trained in flexible sigmoidoscopy during family medicine residency. One physician proctored in colonoscopy by general surgeon. This physician trained the other physicians in colonoscopy

One physician was trained in residency program. Training was not reported for the other physician

Training was variable. Physicians proctored by a variety of specialists to include family physicians, internists, general surgeons, gastroenterologists
73\%-93\%). ${ }^{36}$ The reach-the-cecum rate for the attending endoscopist performing the colonoscopies without ow was $97 \%$. In 2003 another series reported on colonoscopies by 69 "fully trained" endoscostudy, the median cecal intubation rate was $88 \%$ (interquartile range, $83 \%-91 \%$ ). Only $55 \%$ of endoscopists achieved a mean cecal intubation rate of more than $90 \%$, and for $9 \%$ of endoscopists the rate was less than $80 \%$. In a prospective analysis of 13,580 colonoscopies performed by surgical endoscopists, the reach-the-cecum rate was $92 \% .^{38}$

We found an overall reach-the-cecum rate of $89.2 \%$ (95\% CI, 80.1\%-94.4\%) with colonoscopies performed by primary care physicians. In a sensitivity analysis, we recalculated the preceding values for several different subgroups. Most colonoscopies now involve the use of conscious sedation. If only sedated colonoscopies are included, the reachthe-cecum rate rises to $90.5 \%(95 \% \mathrm{CI}$, $83.1 \%-94.8 \%)$. One study was an outlier with a reach-the-cecum rate of only $48.7 \%$. This study involved cases collected between 1985 and 1990, much earlier than the other studies, and the poor results may have been due to lesser technology or older techniques. If this 
Figure 2. Forest plot of adenoma detection rates.

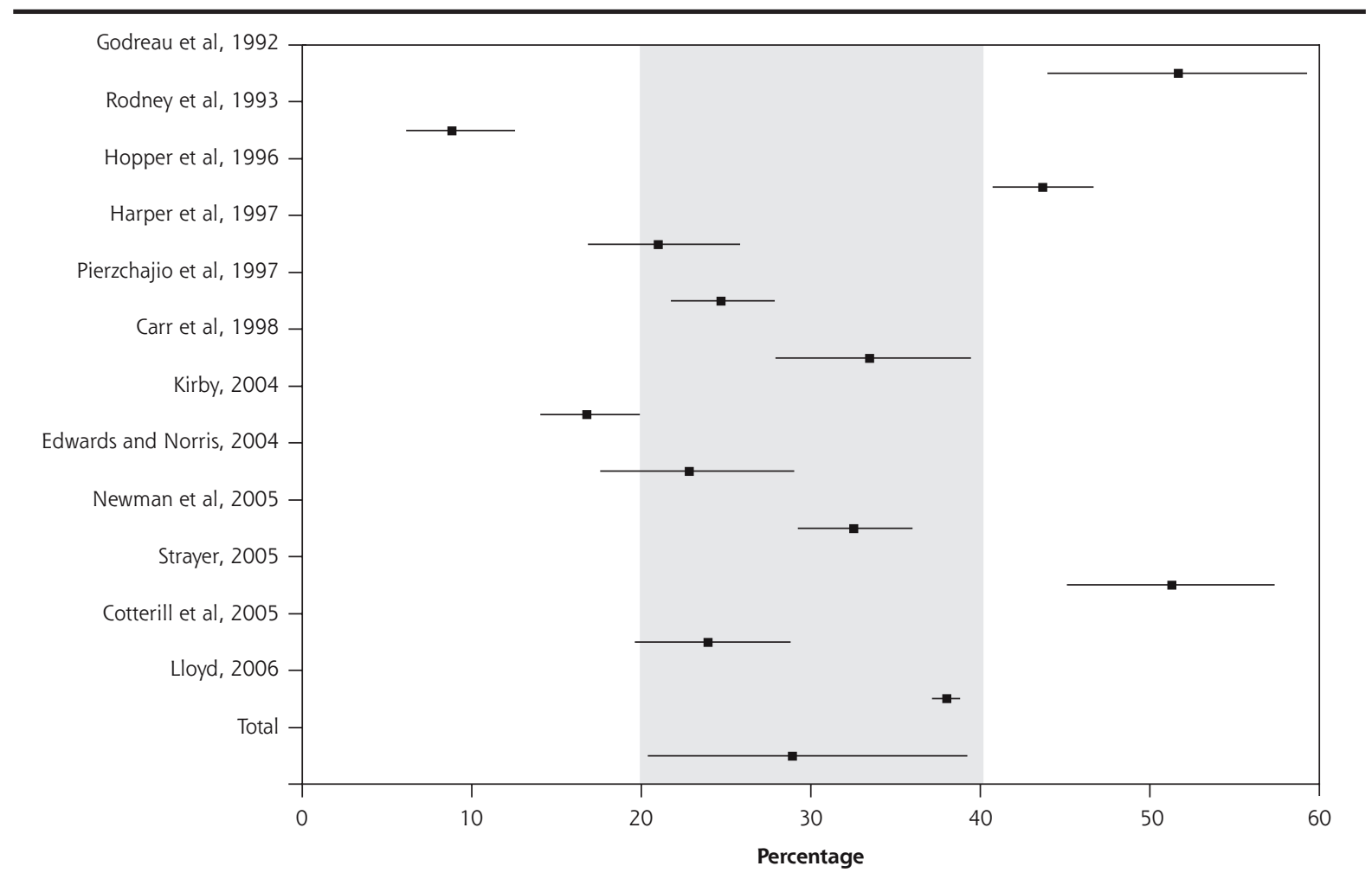

Figure 3. Forest plot of reach-the-cecum rates.

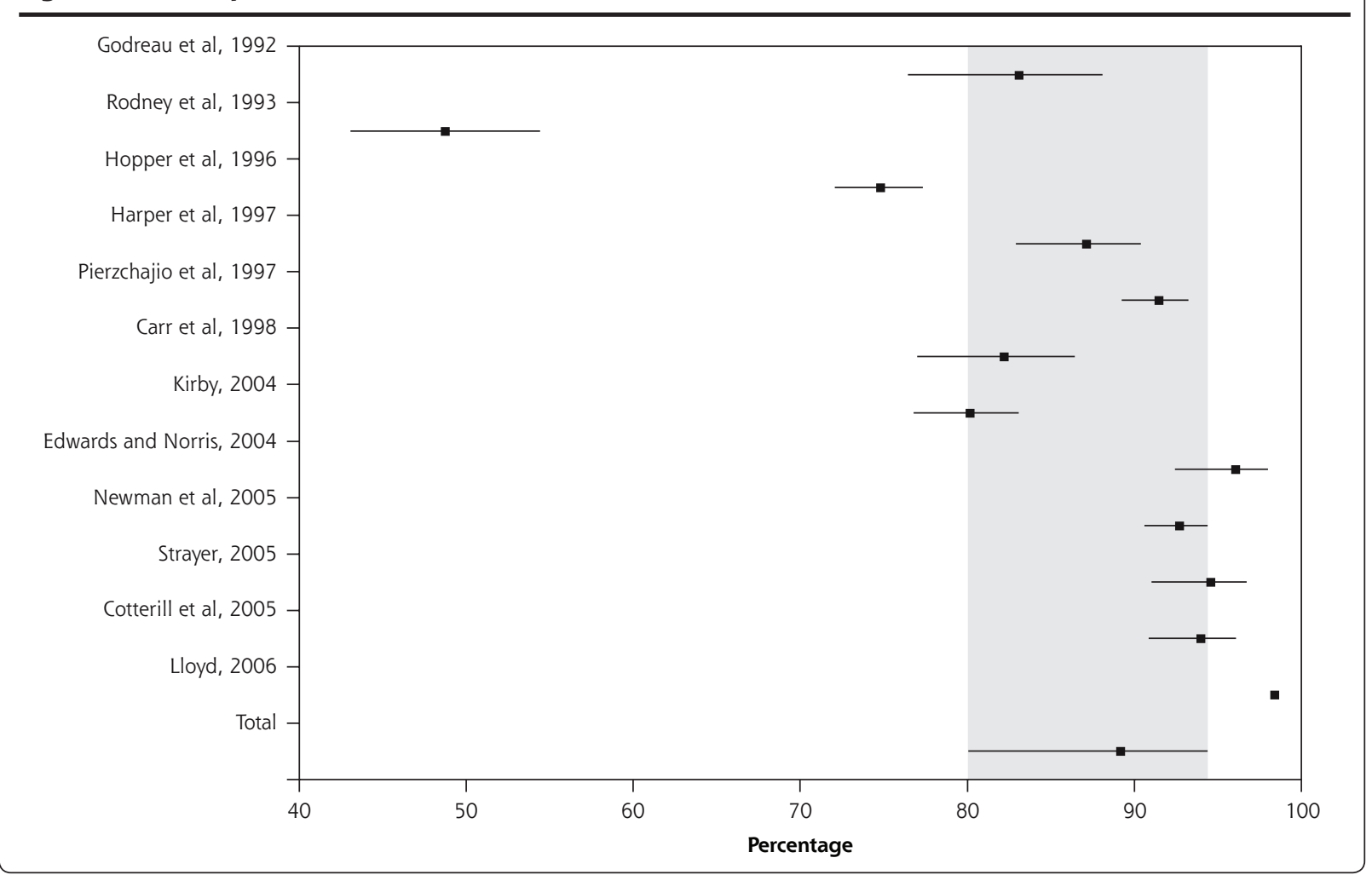


study is excluded, the overall reach-the-cecum rate is 92.0\% (95\% CI, 86.7\%-95.3\%).

The adenoma detection rate is an important quality indicator for the effectiveness of colonoscopy because the goal of colonoscopy is to detect neoplastic lesions and remove polyps. The estimated adenoma detection rate in our meta-analysis is $28.9 \%$ (95\% CI, $20.4 \%$ $39.3 \%$ ). If one study (an outlier with adenoma detection rate of $8.8 \%$ ) is excluded, the adenoma detection rate increases to $31.7 \%$ (95\% CI, 24.0\%-40.7\%). This detection rate is within the recommended rates by the Taskforce on Quality in Endoscopy. ${ }^{19}$ Practice variability is also found among specialists, however. There are disparities in detection rates among gastroenterologists in private practice $(9.4 \%$ to $32.7 \%)$ and those in academic practice ( $25 \%$ to $40 \%) .{ }^{17,19}$ The adenoma detection rate has been reported as $34.2 \%$ by surgical endoscopists. ${ }^{38}$

The complication rates for colonoscopy in this series were well within suggested quality indicators. ${ }^{19}$ The overall bleeding risk for postpolypectomy bleeding should be less than $1 \%$, and most instances can be managed nonoperatively. ${ }^{19}$ Available data suggest that perforation rates should be less than $0.2 \%$ overall or $0.1 \%$ in screening colonoscopies. ${ }^{19}$ There were 7 major complications in the 18,292 colonoscopies in this series (0.04\%). Four complications (0.02\%) involved bleeding from a polypectomy site. These patients were managed nonoperatively and were electively hospitalized overnight. Transfusion was not required in these cases. In this series 3 perforations occurred $(0.02 \%)$. The first perforation was diagnosed at the time of the colonoscopy and was managed without surgery. The other 2 perforations were repaired surgically: 1 perforation was identified at the time of the colonoscopy, and the other perforation was identified 1 week after the procedure. There were no deaths.

There are several limitations to our review. Most colonoscopies were performed by family physicians; other primary care specialties may have been underrepresented in our search strategy. There may have been publication bias that affected our primary outcomes; however, we contacted experts in the field for unpublished studies to supplement our search. Additionally, our funnel plots were symmetric for adenoma detection rates and reach-the-cecum rates, indicating an absence of publication bias for these outcomes. Our results apply to primary care physicians who had colonoscopy training and are not generalizable to all primary care physicians. Colonoscopy training varied considerably among studies and was inconsistently reported. Training included self-study, didactic courses, continuing medical education courses, model training, and proctored procedures by mostly general surgeons or occasionally by family physician endoscopists and rarely by gastroenterologists. Most studies did not report the numbers of colonoscopies completed during training. Because this study is a meta-analysis of case-control and cohort studies, the results are subject to the limitations of these types of studies, including lack of randomization and possibility for confounding variables. Our comprehensive search of the literature, however, found only observational study data, and no randomized clinical control trial was found.

Patient preference, cost, and other factors (eg, comorbidities, life expectancy) should be considered when contemplating a population-based colorectal cancer screening program. Although there appears to be a national move toward colonoscopy as the preferred method for colorectal cancer screening, other modalities remain acceptable screening methods. Yet, less than one-third of the US population is currently completing recommended colorectal cancer screening tests of any kind, and even fewer are screened by colonoscopy. Currently, there are insufficient numbers of endoscopists in the United States to implement a full-scale national screening program. With slightly more than 12,000 board-certified gastroenterologists in the United States, the capacity for a national endoscopic colorectal cancer screening program is limited. Any national screening program should consider all available and proven modalities for screening, eg, fecal occult blood tests.

Colonoscopies performed by primary care physicians are safe and effective. Quality indicators are well within the range of published literature for those performed by specialists and the parameters recommended by expert consensus. With the current need for greater access to colorectal cancer screening and the growing body of evidence for colonoscopy as the screening modality of choice, primary care physicians trained in colonoscopy can play a fundamental role in providing access to colonoscopy for colorectal cancer screening.

To read or post commentaries in response to this article, see it online at http://www.annfammed.org/cgi/content/full/7/1/56.

Key words: Colonoscopy; colorectal cancer; physicians, family; internist; general practitioners; primary care physicians; primary health care; mass screening

Submitted: January 17, 2007; submitted, revised, July 25, 2008; accepted August 4, 2008.

The results of this study have been presented at the North American Primary Care Research Group meeting, October 2006.

Funding support: For the academic year of 2006, part of Dr Taylor's time was supported by a grant from Health Resources and Services Administration Academic Units (grant 2 D12 HP 00023-04) while at the Medical University of South Carolina, Charleston, South Carolina. 


\section{References}

1. American Academy of Family Physicians (AAFP). Summary of Recommendations for Clinical Preventive Services. Rev 6.0. Leawood, KS: American Academy of Family Physicians (AAFP); 2005

2. Pignone M, Rich M, Teutsch SM, Berg AO, Lohr KN. Screening for colorectal cancer in adults at average risk: a summary of the evidence for the US Preventive Services Task Force. Ann Intern Med. 002;137(2):132-141.

3. Rex DK, Johnson DA, Lieberman DA, Burt RW, Sonnenberg A. Colorectal cancer prevention 2000: screening recommendations of the American College of Gastroenterology. American College of Gastroenterology. Am J Gastroenterol. 2000;95(4):868-877.

4. Smith RA, Cokkinides V, Eyre HJ. American cancer society guidelines for the early detection of cancer, 2005. CA Cancer J Clin. 2005;55(1):31-44.

5. Jemal $A$, Siegel R, Ward E, Murray $T, X u$ J, Thun MJ. Cancer statistics, 2007. CA Cancer J Clin. 2007;57(1):43-66.

6. U.S. Preventive Services Task Force. Screening for colorectal cancer: recommendations and rationale. Ann Intern Med. 2002;137(2):129-131

7. Winawer $S$, Fletcher R, Rex D, et al. Colorectal cancer screening and surveillance: clinical guidelines and rationale-update based on new evidence. Gastroenterology. 2003;124(2):544-560.

8. Imperiale TF, Wagner DR, Lin CY, Larkin GN, Rogge JD, Ransohoff DF. Risk of advanced proximal neoplasms in asymptomatic adults according to the distal colorectal findings. $N$ Engl J Med. 2000;343(3):169-174.

9. Lieberman DA, Smith FW. Screening for colon malignancy with colonoscopy. Am J Gastroenterol. 1991;86(8):946-951.

10. Lieberman DA, Weiss DG, Bond JH, Ahnen DJ, Garewal H, Chejfec $\mathrm{G}$. Use of colonoscopy to screen asymptomatic adults for colorectal cancer. Veterans Affairs Cooperative Study Group 380. N Engl J Med. 2000;343(3):162-168.

11. Rex DK, Khan AM, Shah P, Newton J, Cummings OW. Screening colonoscopy in asymptomatic average-risk African Americans. Gastrointest Endosc. 2000;51(5):524-527.

12. Sonnenberg A, Delco F, Inadomi JM. Cost-effectiveness of colonoscopy in screening for colorectal cancer. Ann Intern Med. 2000; 133(8):573-584.

13. Thiis-Evensen E, Hoff GS, Sauar J, Langmark F, Majak BM, Vatn $\mathrm{MH}$. Population-based surveillance by colonoscopy: effect on the incidence of colorectal cancer. Telemark Polyp Study I. Scand J Gastroenterol. 1999;34(4):414-420

14. Winawer SJ, Zauber AG, Ho MN, et al. Prevention of colorectal cancer by colonoscopic polypectomy. The National Polyp Study Workgroup. N Engl J Med. 1993;329(27):1977-1981.

15. Brown ML, Klabunde CN, Mysliwiec P. Current capacity for endoscopic colorectal cancer screening in the United States: data from the National Cancer Institute Survey of Colorectal Cancer Screening Practices. Am J Med. 2003;115(2):129-133

16. American Cancer Society. Cancer Facts \& Figures 2006. http://cancer org/docroot/STT/content/STT_1x_Cancer_Facts__Figures_2006.

17. Barclay RL, Vicari JJ, Doughty AS, Johanson JF, Greenlaw RL. Colonoscopic withdrawal times and adenoma detection during screening colonoscopy. N Engl J Med. 2006;355(24):2533-2541.

18. Citarda F, Tomaselli G, Capocaccia R, Barcherini S, Crespi M. Efficacy in standard clinical practice of colonoscopic polypectomy in reducing colorectal cancer incidence. Gut. 2001;48(6):812-815.

19. Rex DK, Petrini JL, Baron TH, et al. Quality indicators for colonoscopy. Gastrointest Endosc. 2006;63(4)(Suppl):S16-S28.
20. The Joint Advisory Group on GI Endoscopy. Standards for Training in Endoscopy. http://www.thejag.org.uk. Accessed: May 5, 2008.

21. Jadad AR, Moore RA, Carroll D, et al. Assessing the quality of reports of randomized clinical trials: is blinding necessary? Control Clin Trials. 1996;17(1):1-12.

22. Juni $P$, Witschi $A$, Bloch $R$, Egger $M$. The hazards of scoring the quality of clinical trials for meta-analysis. JAMA. 1999;282(11):1054-1060.

23. Stroup DF, Berlin JA, Morton SC, et al. Meta-analysis of observational studies in epidemiology: a proposal for reporting. Metaanalysis Of Observational Studies in Epidemiology (MOOSE) group. JAMA. 2000;283(15):2008-2012.

24. Godreau CJ. Office-based colonoscopy in a family practice. Fam Pract Res J. 1992;12(3):313-320.

25. Rodney WM, Dabov G, Cronin C. Evolving colonoscopy skills in a rural family practice: the first 293 cases. Fam Pract Res J. 1993; $13(1): 43-52$.

26. Hopper W, Kyker KA, Rodney WM. Colonoscopy by a family physician: a 9-year experience of 1,048 procedures. J Fam Pract. 1996;43(6):561-566.

27. Harper MB, Pope JB, Mayeaux EJ Jr, Davis TJ, Myers A, Lirette A. Colonoscopy experience at a family practice residency: a comparison to gastroenterology and general surgery services. Fam Med. 1997;29(8):575-579.

28. Pierzchajlo RP, Ackermann RJ, Vogel RL. Colonoscopy performed by a family physician. A case series of 751 procedures. J Fam Pract. 1997;44(5):473-480.

29. Carr KW, Worthington JM, Rodney WM, Gentry S, Sellers A, Sizemore J. Advancing from flexible sigmoidoscopy to colonoscopy in rural family practice. Tenn Med. 1998;91(1):21-26

30. Kirby E. Colonoscopy procedures at a small rural hospital. Can J Rural Med. 2004;9(2):89-93.

31. Edwards JK, Norris TE. Colonoscopy in rural communities: can family physicians perform the procedure with safe and efficacious results? J Am Board Fam Pract. 2004;17(5):353-358.

32. Newman RJ, Nichols DB, Cummings DM. Outpatient colonoscopy by rural family physicians. Ann Fam Med. 2005;3(2):122-125.

33. Strayer, SM, Patterson, D, Kington, ML. Who Should Perform Screening Colonnoscopies? A Comparison of Outcomes Among Different Specialties. Paper presented at: NAPCRG 2004. Proceedings of the 32nd Annual North American Primary Care Group; 2004 Oct 10-13; Orlando, FL.

34. Cotterill M, Gasparelli R, Kirby E. Colorectal cancer detection in a rural community. Development of a colonoscopy screening program. Can Fam Physician. 2005;51:1224-1228.

35. Lloyd SC. Seeking Cecums II, A Success Story Addressing the Manpower Needs Towards Achieving Colon Cancer Screening Goals of Healthy People 2010. UICC World Cancer Congress 2006. Bridging the Gap: Transforming Knowledge into Action. Washington DC. 2006. http://2006.confex.com/uicc/uicc/techprogram/P6194.HTM. Accessed Feb 15, 2007

36. Marshall JB. Technical proficiency of trainees performing colonoscopy: a learning curve. Gastrointest Endosc. 1995;42(4):287-291.

37. Cotton PB, Connor P, McGee D, et al. Colonoscopy: practice variation among 69 hospital-based endoscopists. Gastrointest Endosc. 2003;57(3):352-357.

38. Wexner SD, Garbus JE, Singh JJ. A prospective analysis of 13,580 colonoscopies. Reevaluation of credentialing guidelines. Surg Endosc. 2001;15(3):251-261. 